\title{
A journey into causes of corporate misbehaviour
}

\author{
Citation for published version (APA):
}

van Aartsen, C. W. (2020). A journey into causes of corporate misbehaviour: Why corporate legal disciplines and regulation need to be structurally reformed. [Doctoral Thesis, Maastricht University]. ProefschriftMaken. https://doi.org/10.26481/dis.20201014ca

Document status and date:

Published: 01/01/2020

DOI:

10.26481/dis.20201014ca

Document Version:

Publisher's PDF, also known as Version of record

\section{Please check the document version of this publication:}

- A submitted manuscript is the version of the article upon submission and before peer-review. There can be important differences between the submitted version and the official published version of record.

People interested in the research are advised to contact the author for the final version of the publication, or visit the DOI to the publisher's website.

- The final author version and the galley proof are versions of the publication after peer review.

- The final published version features the final layout of the paper including the volume, issue and page numbers.

Link to publication

\footnotetext{
General rights rights.

- You may freely distribute the URL identifying the publication in the public portal. please follow below link for the End User Agreement:

www.umlib.nl/taverne-license

Take down policy

If you believe that this document breaches copyright please contact us at:

repository@maastrichtuniversity.nl

providing details and we will investigate your claim.
}

Copyright and moral rights for the publications made accessible in the public portal are retained by the authors and/or other copyright owners and it is a condition of accessing publications that users recognise and abide by the legal requirements associated with these

- Users may download and print one copy of any publication from the public portal for the purpose of private study or research.

- You may not further distribute the material or use it for any profit-making activity or commercial gain

If the publication is distributed under the terms of Article $25 \mathrm{fa}$ of the Dutch Copyright Act, indicated by the "Taverne" license above, 


\section{Appendix: Detailed summary}

This appendix provides a detailed summary of each Chapter.

\section{Chapter 1: Introduction}

The introduction opened with a historical discussion on the corporation and its potential as a market-distorting actor. ${ }^{8}$ We identified that decision-making through presumedly selfinterested agents means that corporations are structurally incapable of efficiently pursuing their own individual self-interest. If economic liberalism is the dominant blueprint for the efficient market regulation of contemporary liberal democracies, then it stands to reason that corporations may introduce market inefficiencies due to their inability to maximise their own self-interest. These inefficiencies, in addition to corporate status as a privileged atypical market actor, historically generated a large degree of scepticism in relation to corporations.

This scepticism has abated over time but emerges intermittently in times of economic crisis, following corporate scandals or as part of discussions on the social responsibility of corporations. However, instead of examining corporations as potentially market-distorting actors, corporate legal scholarship typically debates the nature of the corporate form and whether it is a public or private actor. A historical review of prominent US theories in these debates showed how approaches to these issues have changed over time. ${ }^{9}$

First modelled in the $18^{\text {th }}$ century as a public concession from the state, corporations were subsequently viewed as private natural entities, natural entities with public obligations, private owner-trustee entities and most recently as a private nexus of contracts from around the 1980s onwards. Interestingly, shifts in these theories coincided with transitions in the dominant form of capitalism and economic theory. This suggested that we should not examine these theories in isolation of their social, economic, cultural and historical context. This invited us to reflect on transnational capitalism as the contemporary context of corporate activities.

Transnational capitalism is marked by the transnational production of goods and provision of services without the accompanying development of a global state or government. ${ }^{10}$ Its transnational architecture is characterised by strong protections for economic liberalisation, free trade and free movement of capital, and relatively weak protections for issues of social and environmental concern. The core of its legal foundation may be found in an international patchwork of trade and investment agreements. It is able to transcend

\footnotetext{
8 See section 1.1.

${ }^{9}$ See section 1.2 .

${ }^{10}$ See section 1.3.
} 
national borders due to a transnational capitalist consensus which has emerged out of the discussion, development and practice of influential states, inter-governmental organisations, corporate lobby groups and other bodies such as the US, EU, OECD, World Bank, International Monetary Fund (IMF) and World Trade Organisation (WTO).

The transition to transnational capitalism has been intertwined with the growth and development of TNCs with transnational production and supply chains. One significant enabling factor is the way that trade and investment agreements have made corporations largely free to choose where to operate and invest. This introduced competitive market dynamics between states seeking to attract the largest degree of international investment. Such a dynamic can generate efficiencies, but it also incentivises states to attract corporations and other forms of foreign investment by 'racing to the bottom' and minimising labour protections and environmental regulations. This has produced a 'governance gap' between the harms caused by corporate activities and the relative inability or unwillingness of 'weak' nation states to constrain corporate activities at the national or international level.

Although the transnational capitalist context is essential for understanding contemporary corporate activities, we also emphasised that major structural changes in the corporate form have been achieved through legal changes in $\mathrm{CL}$, and more recently through $\mathrm{CG}$ and CSR. This led us to examine the basic purposes, characteristics and scientific content of these disciplines. ${ }^{11}$ We identified that the three corporate legal disciplines are dedicated towards the public interest, with CL adopting a national orientation and CG and CSR adopting an international orientation.

$\mathrm{CL}$ is traditionally hard law and operates within the nation state structure. It establishes the governance model of corporations and fundamental characteristics of the corporate form as well as a host of technical and organisational elements. CG is less reliant on hard law and primarily focuses on the efficient governance of corporations by addressing the economic problem of separation between ownership and control; i.e. how can corporate agents be made responsive to the interests of shareholders. It is explicitly shareholder oriented, and the legal form and effect of its measures can range from hard law to soft law and self-regulation. It recognises a wide range of norm-creating parties, including states, business and NGOs, and is open to the influence of non-state legal and quasi-legal instruments. This makes CG is free to articulate at the international level but limits the degree of its legal enforceability. CSR focuses on the social responsibility of corporations and their relationship to the genesis, continuation and global intensification of a wide variety of social, environmental, political and economic crises. Its policies typically approach these problems from an economic perspective, viewing them as issues of

\footnotetext{
${ }^{11}$ See section 1.4 .
} 
inefficiency and market failure. It also adopts a mix of legal forms and relies on a variety of norm-creating parties, enabling it to operate at the international level with limited enforceability.

The emergence of CG and CSR may be considered fortuitous in relation to escalating crises and the absence of a global state. ${ }^{12}$ Using the universalist market-based approaches of economic theory, these disciplines outline the conditions under which corporations across the world can compete efficiently and minimise governance issues and social and environmental externalities. If done correctly, this should generate a win-win for corporations, society and the environment. By severing their connection to traditional conceptions of the state-territorial nexus for legislation, these disciplines provide academics, policy makers and legislators with a global foundation for promoting sustainable development and improving corporate functioning. CG and CSR may therefore be able to collectively counteract the negative effects of the governance gap on corporate performance and social and environmental regulation.

The issue may not, however, be so straightforward. A complementary interpretation suggests that CG and CSR may be playing a contradictory dual functionality in relation to these developments. First, their rise to prominence has coincided with the emergence of transnational capitalism from around the 1980s onwards. Second, their development has mirrored the way that influential states, inter-governmental organisations, corporate lobby groups and other bodies have articulated the transnational capitalist consensus. Third, they are articulated by similar parties and their theoretical foundation is the same set of economic theories that is used to justify and promote transnational capitalist consensus in terms of competition, economic liberalisation, free trade and free movement of capital. This means that CG and CSR, in seeking to improve corporate performance and address social and environmental issues under conditions of globalisation, have relied on and lent credence to the very theories which set in motion the international race to the bottom and produced the governance gap and weaker nation states in the first place. This suggests that CG and CSR both constitute and address the governance gap in their efforts to promote sustainable development and efficient corporate functioning.

Whether this is problematic depends on the extent to which these disciplines, in combination with corporate law, are succeeding in closing the governance gap and aligning corporate activities with the public interest. If these disciplines are failing in this alignment, then they could be contributing more towards the genesis than resolution of corporate issues, in which case global social, economic and environmental crises demand that these disciplines and their concomitant regulation be reformed. We presumed that

\footnotetext{
${ }^{12}$ See section 1.5 .
} 
the public interest is reflected in the content of corporate legal instruments so we could explore these issues in the following MRQs:

MRQ1: Are corporate law, corporate governance and corporate social responsibility successfully aligning transnational corporate behaviour with corporate legal behavioural expectations?

MRQ2: If corporate law, corporate governance and corporate social responsibility are not succeeding, then what can we do about this?

We subsequently outlined a research design with various sub-questions to address these MRQs:

1) How do corporate law, corporate governance and corporate social responsibility expect transnational corporations to behave?

2) Is there a misalignment between transnational corporate behaviour and corporate legal expectations?

3) If it exists, what are some of the corporate legal causes of the misalignment between behaviour and expectations?

4) If it exists, what are some of the non-corporate legal causes of the misalignment between behaviour and expectations?

5) Are corporate law, corporate governance and corporate social responsibility successfully aligning transnational corporate behaviour with corporate legal behavioural expectations? (MRQ1)

6) If corporate law, corporate governance and corporate social responsibility are not succeeding, then what can we do about this? (MRQ2)

Each of these sub-questions was addressed in six successive Chapters.

\section{Chapter 2: Corporate legal expectations of transnational corporate behaviour}

Chapter 2 examined how CL, CG and CSR expect TNCs to behave. Its first section defined the following key terms: corporate law, corporate governance, corporate social responsibility, 'corporate behaviour' and 'expectations of corporate behaviour'. ${ }^{13}$ The second section outlined methods for selecting expectations. ${ }^{14}$ It indicated what legislation would be examined, how we would select appropriate expectations, how we would classify expectations and why we would also examine convergence vs. divergence discussions for each discipline.

\footnotetext{
${ }^{13}$ See section 2.1 .

${ }^{14}$ See section 2.2.
} 
This established that the third section, on corporate law expectations of TNC behaviour, would examine the national legislation of the United States (US), United Kingdom (UK), Germany and the Netherlands. ${ }^{15}$ It would also outline the models for the governance of corporations for each jurisdiction and present illustrative samples of 'prime' expectations which significantly influence corporate behaviour (hereafter ExpCB). This would be accompanied by an inventory of prominent legal instruments as well as a selection of ExpCB which establish the characteristics of the corporate form, the range of corporate power and govern corporate agent selection, authority and fiduciary duties in these jurisdictions. We therefore discussed the US shareholder primacy model, UK enlightened shareholder model, German co-determination model and Dutch real entity model as well as how these models influence corporate decision-making and activities. It was straightforward to identify provisions for four of the five fundamental characteristics for corporations: separate legal personality, limited liability, delegated management under a board structure and transferable shares. The fifth characteristic on investor ownership was contested but we could nevertheless determine for each jurisdiction that shareholders are ultimately in charge of corporate decision-making due to their influence over the board of directors. We noted that each jurisdiction subjected agents to fiduciary duties and empowered them to engage in lawful activities on behalf of the corporation. We closed with a discussion on whether $\mathrm{CL}$ is converging or diverging between countries and identified that there is an international normative convergence on the superiority of the shareholder model for the governance of corporations. The overall finding of this section was that CL ExpCB are both enabling and constraining; they constitute and limit the potential range of corporate behaviour. It is within this contradictory dual functionality that corporations are empowered to engage in a broad range of lawful activities. The lawfulness of these activities is important; compliance with the law may be considered the most fundamental ExpCB.

The section on corporate governance started by identifying a range of prominent national and international legal CG instruments. ${ }^{16}$ It explained that these instruments share an emblematic worldview derived from the international normative convergence on shareholder primacy and are primarily directed at resolving the problem of separation between ownership and control. This worldview subsequently enabled us to use the highly influential OECD Principles of Corporate Governance as a representative instrument for identifying prime CG ExpCB. We examined four sections of this document: the rights and equitable treatment of shareholders and key ownership functions; the role of stakeholders in corporate governance; disclosure and transparency; and, the responsibilities of the board. ExpCB in these sections generally established that

\footnotetext{
${ }^{15}$ See section 2.3.

${ }^{16}$ See section 2.4.
} 
corporations should adopt CG best practices to protect and facilitate shareholder decisionmaking and information rights. Shareholders should, moreover, be treated equally and given the opportunity to obtain redress for violations of their rights. Material information which impacts economic decision-making should be disclosed to promote efficient market functioning and assist shareholders and other parties in making decisions. Stakeholder interests should be respected and, where possible, used as an instrument to further the interests of shareholders and the corporation. The board of directors should work to ensure adequate shareholder returns, monitor corporate management and prevent conflicts of interest from affecting governance processes; board objectivity and independence are highly valued in this regard. The Principles indicate that the adoption of these ExpCB is good for shareholders, good for corporate profitability and efficiency, good for market functioning and therefore good for society as a whole.

The section on corporate social responsibility first presented a range of prominent national and international legal instruments. ${ }^{17}$ It subsequently selected and examined the OECD Guidelines for Multinational Enterprises and EC Communication on CSR as influential representative instruments to generate prime CSR ExpCB. Both documents are unenforceable soft law, but they place a considerable degree of responsibility on corporate shoulders for addressing social, environmental and economic issues. They indicate that corporations should implement due diligence to identify, prevent and mitigate the adverse impacts of their own activities and in their supply chain for virtually every area of contemporary social, environmental and economic concern. This includes human rights, environmental impacts such as emissions and waste management, labour relations, taxation, corruption, competition and so on. The Guidelines and Communication establish that governments should play a supportive role and develop market incentives to stimulate the expansion of corporate activities into these areas. The overarching expectation of both instruments is that corporations pursue market pressures and incentives within the hard law framework in a way that suits both their bottom line and addresses social, environmental and economic problems. This includes compliance with the law, disclosure of material information and the adoption of CSR best practices. If done appropriately, compliance with CSR ExpCB will allow corporations to benefit economically from increased profits, customer and employee loyalty, reputational advantages, cost benefits and a range of other competitive advantages.

The prime ExpCB of these three disciplines are complementary. TNCs are expected to comply with all these expectations in their hard or soft law form.

\footnotetext{
${ }^{17}$ See section 2.5.
} 


\section{Chapter 3: Misalignment between corporate legal expectations and transnational corporate behaviour}

Chapter 3 examined whether TNCs do, in fact, act in accordance with these expectations. To do so, it qualitatively assessed whether there is misalignment between CL, CG and CSR ExpCB and TNC behaviour. The first section, on methods for examining whether there is alignment between corporate legal expectations and transnational corporate behaviour, established how we would evaluate misalignment for each corporate legal discipline. ${ }^{18}$ For $\mathrm{CL}$, we examined whether TNCs comply with the law. For CG and CSR, we estimated the extent to which TNCs are adopting best practices. The second, third and fourth sections of this Chapter presented findings for each discipline.

The second section, on the alignment of corporate law expectations and transnational corporate behaviour, revealed egregious examples of systemic TNC illegality: money laundering, illicit capital flows, tax evasion, cartels, anti-competitive behaviour, pervasive espionage, bribery and corruption. ${ }^{19}$ This limited range of examples was sufficient to determine that TNC illegality is pervasive and harmful. Non-compliance with the public, constraining aspects of $\mathrm{CL}$ is incidental as well as structural, with instances of illegality occurring at the local, national and global scale. We cannot describe its precise magnitude, but evidence suggests that there is a substantial misalignment between CL ExpCB and TNC behaviour.

The third section, on the alignment of corporate governance expectations and transnational corporate behaviour, used trends and figures on TNC adoption of CG best practices to conservatively estimate a participation rate of over $90 \%{ }^{20}$ The findings suggested that there is a generally insubstantial gap between CG expectations and TNC behaviour. The high degree of best practice participation reaffirms the existence of a normative consensus on the shareholder primacy governance model.

The fourth section, on the alignment of corporate social responsibility expectations and transnational corporate behaviour, estimated participation in CSR best practices using figures on the adoption of GRI reporting standards by TNCs. ${ }^{21} \mathrm{~A} 75 \%$ participation rate suggested that roughly one in four TNCs is not engaging in CSR. It is difficult to discern whether this misalignment is substantial because we have no data on the relationship between CSR reporting and the effectiveness of CSR best practices. Nor can we determine that $75 \%$ of TNCs are sustainable or that $25 \%$ are unsustainable. It is, after all, possible for TNCs to report in accordance with GRI but still exhibit low social and environmental

\footnotetext{
18 See section 3.1.

19 See section 3.2 .

20 See section 3.3.

${ }^{21}$ See section 3.4 .
} 
performance. We can, however, be confident that there is a degree of misalignment between CSR expectations and TNC behaviour, and that this misalignment is much more substantial for CSR than CG.

It is remarkable that we found systemic TNC illegality despite near universal participation in CG best practices and a CSR best practice adoption rate of around $75 \%$. This stands in awkward contrast to the aim of prominent CG and CSR instruments to improve corporate trustworthiness, transparency, accountability and sustainability. If anything, these documents emphasise that a high degree of CG and CSR participation should be linked to high levels of desirable corporate behaviour.

We discussed various potential explanations for this discrepancy but ultimately argued that CG and CSR theories may not adequately describe corporations and the corporate context, leading them to overestimate their positive impact on TNC behaviour. TNC adoption of CG and CSR best practices may have little impact on pervasive and systemic corporate illegality if the theoretical basis of CG and CSR, and perhaps CL, is flawed. Chapters 4 and 5 tested this explanation by investigating and contrasting how CL, CG, CSR and other disciplines account for the misalignment between TNC behaviour and ExpCB.

\section{Chapter 4: Corporate legal causes of misalignment}

Chapter 4 sought to explain misalignment by identifying corporate legal causes of TNC misbehaviour; i.e. how do CL, CG and CSR account for the discrepancy between desired and actual corporate behaviour? The first section defined key terms such as 'misbehaviour' and 'causes of misbehaviour'; it positioned misbehaviour as a contingent concept whose content varies between disciplines. ${ }^{22}$

The second section established a two-step method for identifying causes of misbehaviour. ${ }^{23}$ Step one extrapolates from prominent corporate legal instruments how they may directly or indirectly address corporate misbehaviour. Step two adds context by consulting academic literature for theories on the way that corporate legal instruments attempt to address misbehaviour. The findings of both steps are combined to identify causal mechanisms for corporate misbehaviour. The three subsequent sections adopted this two-step method to identify causes of TNC misbehaviour for CL, CG and CSR.

The third section, on corporate law causes of misbehaviour, examined prominent legal instruments and found three categories of $\mathrm{CL}$ provisions which directly and indirectly address systemic TNC illegality: provisions on behavioural standards; provisions on

\footnotetext{
${ }^{22}$ See section 4.1 .

${ }^{23}$ See section 4.2.
} 
internal control and monitoring; and, provisions on external control and monitoring. ${ }^{24}$ Academic literature subsequently indicated that the provisions within these categories could be divided into two approaches: legal or market-based. The following causes of misbehaviour were identified from these findings:

1) Misbehaviour may occur when corporate agents act against the interests of the corporation, shareholders and other investors;

2) Misbehaviour may occur when it does not harm corporate interests or the interests of parties with control and monitoring rights;

3) Misbehaviour may be symptomatic of market failures in the labour market, product market, market for corporate control or the market for corporate securities.

The fourth section, on corporate governance causes of misbehaviour, interpreted misbehaviour as systemic TNC illegality and searched for causes of misbehaviour in the OECD Principles of Corporate Governance and academic literature. ${ }^{25}$ It identified how provisions on shareholder rights, institutional investors, stakeholder rights, board responsibilities, disclosure and transparency rely on the same legal and market-based approaches that $\mathrm{CL}$ uses to address misbehaviour. Causes of misbehaviour were inferred from these provisions and approaches, producing a partial overlap with $\mathrm{CL}$ in the following CG causes of misbehaviour:

4) Misbehaviour may occur when corporate agents act against the interests of the corporation, shareholders and other investors;

5) Misbehaviour may occur when it does not harm corporate interests or the interests of parties with control and monitoring rights;

6) Misbehaviour may be symptomatic of market failures in the labour market, product market, market for corporate control or the market for corporate securities;

7) Misbehaviour may occur due to flawed hard law incentives and legal sanctions.

The fifth section, on corporate social responsibility causes of misbehaviour, defined misbehaviour as non-participation in CSR best practices. ${ }^{26}$ It first examined how the OECD Guidelines for Multinational Enterprises and EC Communication on CSR may directly or indirectly address this kind of TNC misbehaviour. These prominent CSR instruments contain a variety of methods to stimulate TNC participation in CSR: corporate benefits; government encouragement; market discipline from demand for sustainable products and

\footnotetext{
24 See section 4.3.

25 See section 4.4 .

${ }^{26}$ See section 4.5 .
} 
services; and, third party encouragement such as National Contact Points. Second, this section examined academic literature and recognised that core CSR concepts for guiding corporate behaviour - the 'business case' and voluntary or 'smart mix' regulatory approaches - are sustainability-oriented iterations of the same legal and market-based approaches which underpin CL and CG. The following CSR causes of misbehaviour were inferred from these findings:

8) Misbehaviour may be symptomatic of market failures in the labour market, product market, market for corporate control or the market for corporate securities;

9) Misbehaviour may occur due to flawed hard law incentives and legal sanctions.

We ultimately identified that CL, CG and CSR rely on similar legal and market-based approaches to address TNC misbehaviour. We eliminated overlaps stemming from this similarity and produced the following, condensed list of corporate legal causes of TNC misbehaviour:

Cause 1) Misbehaviour may occur when corporate agents act against the interests of the corporation, shareholders and other investors;

Cause 2) Misbehaviour may occur when it does not harm corporate interests or the interests of parties with control and monitoring rights;

Cause 3) Misbehaviour may be symptomatic of market failures in the labour market, product market, market for corporate control or the market for corporate securities;

Cause 4) Misbehaviour may occur due to flawed hard law incentives and legal sanctions.

These corporate legal causes capture how prominent legal instruments in CL, CG and CSR interpret the misalignment between ExpCB and TNC behaviour that was identified in Chapter 3. They represent the main techniques and points of intervention that these disciplines use to prevent systemic TNC illegality and promote participation in best practices. The fact that we found misalignment indicates that these techniques are not currently effective in aligning ExpCB and TNC behaviour. This suggests that corporate legal disciplines may be failing to align TNC behaviour with the public interest. We did not, however, automatically attribute this failure in alignment to CL, CG and CSR. We recognised that other factors such as individual behaviour, inadequate social and environmental regulation or poor legal enforcement could also be responsible. Chapters 5 and 6 addressed this issue of attribution as part of their research design. 


\section{Chapter 5: Non-corporate legal causes of misalignment}

Chapter 5 produced a list of causes of misbehaviour from 'non-corporate legal' disciplines (i.e. not from CL, CG or CSR) to explain misalignment between ExpCB and TNC behaviour. The first section, on methods for identifying non-corporate legal causes, outlined how we could use non-exhaustive, explanatory approaches to identify appropriate causes from the vast academic literature of non-corporate legal disciplines. ${ }^{27}$ It established that appropriate causes are those whose absence could be attributed to shortcomings in the legal substance and theoretical design of corporate legal disciplines and regulation. We used Kuhn's concept of disciplinary matrices to develop a method for selecting this type of appropriate causes.

Kuhn's theories indicate that researchers, as members of a scientific community, rely on a common worldview and various axiomatic assumptions to define the scope of their community's research. These axioms determine what is, or is not, included as part of a community's scientific practice; an axiom that individuals are rational, for example, prevents the systemic inclusion of research which assumes that individuals are irrational. The 'missing substance' of reality that is precluded by the axioms of a scientific community's disciplinary matrix can be used to identify the limits of their scientific practice. If a disciplinary matrix relies on an axiom ' $X$ ', then its missing substance can be identified by building on an axiom 'not X.'

Transposing these findings into the corporate legal context, we recognised that corporate legal researchers are members of a scientific community which is bound together by common reliance on a 'corporate legal disciplinary matrix' (CLDM). The axioms of this CLDM can be derived from the legal and market-based approaches which underpin prominent corporate legal instruments. These axioms can subsequently be used to identify the missing substance of reality which is precluded from the scope of corporate legal analysis. Appropriate non-corporate legal causes can be selected from this missing substance since their absence from the CLDM can be attributed to shortcomings in the legal substance and theoretical design of CL, CG and CSR.

Following this process, we first inferred six axiomatic assumptions from the corporate legal causes of the previous Chapter:

Axiom 1) Corporate agents are rationally self-interested and capable of free decisionmaking;

Axiom 2) The corporation or corporate form is not responsible for misbehaviour;

${ }^{27}$ See section 5.1. 
Axiom 3) There are only economic interactions between corporations;

Axiom 4) States enable and regulate but are otherwise uninvolved in corporate activities;

Axiom 5) Self-interest modelling is a roughly accurate and neutral approach to modelling human behaviour;

Axiom 6) Markets are desirable and society is and should be organised in accordance with market principles; market interventions are only justified in cases of market failure as interpreted by economic theory.

The second section of this Chapter, on identifying non-corporate legal causes, used these axioms to develop six analytical frameworks using 'not $X$ ' axioms and insights from a range of disciplines including political economy, economics, psychology, anthropology, management studies, sociology, political science, criminology, theology, media studies and philosophy. ${ }^{28}$ The following analytical frameworks adopted an explanatory approach and were outlined in separate sub-sections:

Analytical framework 1) Corporate misbehaviour and the moral autonomy of corporate agents;

Analytical framework 2) Corporate misbehaviour and the contemporary corporate form;

Analytical framework 3) Corporate misbehaviour and corporate class formation;

Analytical framework 4) Corporate misbehaviour and the state-corporate nexus;

Analytical framework 5) Corporate misbehaviour and self-interest as a self-fulfilling prophecy;

Analytical framework 6) Corporate misbehaviour and the political economy and anthropology of markets.

The first analytical framework, on corporate misbehaviour and the moral autonomy of corporate agents, ${ }^{29}$ indicated how the moral capacity of individuals may be impaired by their work as (corporate) agents. It showed how role-based reasoning, fractured autonomy and committee decision-making undermine the extent to which corporate agents are free to make moral decisions. This gave rise to the first non-corporate legal cause of misbehaviour:

\footnotetext{
${ }^{28}$ See section 5.2.

${ }^{29}$ See section 5.2.1.
} 
Cause 1) Misbehaviour may occur because agency roles impair the moral capacity of corporate agents.

The second analytical framework, on corporate misbehaviour and the contemporary corporate form, ${ }^{30}$ reflected on the nature of corporations as social constructs and market actors. It outlined why markets exhibit an anti-social bias and demonstrated that the scope of markets and market exchange defines the limits and range of direct corporate interaction with society. It proposed that corporations are manifested processually through everyday practices and cultural representations such as signing contracts, advertising and so on. The content of these practices and representations is determined by corporate agent interpretation of corporate schematics, i.e. the formal and informal complex of rules, statistics, categories and organisational structures that are present within the scope of a corporate organisation's knowledge and power. These schematics are generally interpreted using narrow, financial calculus in order to achieve three corporate imperatives: survival, profit and growth. We argued that the pursuit of these imperatives is central to understanding systemic corporate harm. These discussions produced three additional non-corporate legal causes:

Cause 2) Misbehaviour may occur when agency roles' moral impairment is augmented by role-based reasoning on the basis of narrow, self-interested financial calculus;

Cause 3) Misbehaviour may arise due to narrow economic interpretations of the contemporary corporate form's universal imperatives for survival, growth and profit;

Cause 4) Misbehaviour may be encouraged by the game-like construction of markets as competitive arenas.

The third analytical framework, on corporate misbehaviour and corporate class formation, ${ }^{31}$ examined how common interests between corporations may transcend and co-exist with competitive market dynamics. After identifying several common interests, this analytical framework presented several examples of corporate class formation: the political-economic development of the US railroad industry around the 1850s; corporate opposition to US President Roosevelt's 'New Deal' in the 1930s and 40s; corporate backing for the elections of pro-business and pro-market reformers Reagan and Thatcher at the end of the 1970s; and, corporate promotion of CSR to deflect strict government regulation in favour of business self-regulation. The following platforms were recognised as mechanisms to promote corporate class formation: interlocking directorships; national and international business associations and lobby groups; multi-stakeholder networks and

\footnotetext{
30 See section 5.2.2.

${ }^{31}$ See section 5.2.3.
} 
public-private partnerships; economic- or business-oriented media organisations; and public relations firms. Two non-corporate legal causes of misbehaviour were identified from these discussions:

Cause 5) Misbehaviour may be promoted by corporate class action in favour of marketbased approaches with their concomitant production of social and environmental externalities;

Cause 6) Misbehaviour may be perpetuated or exacerbated when corporate class action shields corporations from social, political or regulatory intervention.

The fourth analytical framework, on corporate misbehaviour and the state-corporate nexus, ${ }^{32}$ analysed how relationships between states and corporations are more diverse than the mere regulatory relationship usually found in corporate legal analysis. This was demonstrated with reference to historical and contemporary instances of collaboration between TNCs and states to foment civil wars and stimulate armed foreign intervention. Although state-corporate relationships are not inherently problematic, these poignant examples showed how harmful they can be if unchecked. This analytical framework subsequently relied on dissensus theory from criminology to develop an account of the state-corporate nexus in capitalist states. This account emphasised contradictory effects, where capitalist states promote capital accumulation and corporate activities, but constrain these activities if they risk destabilising the social order. Two non-corporate legal causes of misbehaviour emerged from this account:

Cause 7) Misbehaviour may be tolerated or encouraged when it coincides with state interests in profit accumulation and economic growth;

Cause 8) Misbehaviour may be tolerated or encouraged when state interests do not perceive that it upsets the long-term stability and functioning of the capitalist social order.

The fifth analytical framework, on corporate misbehaviour and self-interest as a selffulfilling prophecy, ${ }^{33}$ demonstrated how self-interest assumptions in organisational design may stimulate self-interested behaviour and contribute towards corporate misbehaviour. We found that the performative (i.e. self-fulfilling) effects of self-interested behavioural assumptions, as are commonly used in corporate legal analysis and translated into corporate organisational structures, may incentivise corporate agents to exhibit greater levels of materialistically self-interested behaviour. We subsequently connected this kind of behaviour, via psychological literature, to higher levels of corruption, free-riding and

\footnotetext{
32 See section 5.2.4.

${ }^{33}$ See section 5.2.5.
} 
other forms of anti-social behaviour. This generated an additional non-corporate legal cause of misbehaviour:

Cause 9) Misbehaviour may be stimulated by adopting economic self-interest assumptions in corporate organisational design and corporate schematic interpretation.

The sixth analytical framework, on corporate misbehaviour and the political economy and anthropology of markets, ${ }^{34}$ analysed how reliance on market-based approaches may contribute towards TNC misbehaviour. It showed that perspectives on markets as a prepolitical foundation for human civilisation have formed into an elite consensus on markets as the best approach to organising social arrangements. These market utopian perspectives propose that trade and exchange were the 'first' kind of social interaction, leading subsequently to other forms of interaction and the development of larger societies and political bodies. Political economic and anthropological insights revealed that there is no empirical basis for this proposition; there is no evidence that markets or exchange play a key organising role in pre-state societies. Instead, there is considerable evidence that markets are socially constructed by particular socio-political institutions. It would not, for example, be possible to trade land without land registries, or labour without enforceable contracts; some form of organised authority is required to ensure that land and labour, as well as currency and information, are tradeable commodities. We established that market fundamentalist approaches - which assume that markets are prepolitical and foundational to society - idealise markets and crowd out other forms of social arrangement. They do not recognise that markets have intrinsic shortcomings, as well as advantages, or that markets are simply one of various options that policy makers can use to structure social arrangements. We concluded that it is not possible to create a market utopia because markets stimulate destructive forms of self-interested behaviour and erode the socio-political structures in which they are embedded. We subsequently identified a final non-corporate legal cause of misbehaviour:

Cause 10) Misbehaviour may be positively correlated with the degree to which a society uses market principles to organise social arrangements.

The ten non-corporate legal causes of Chapter 5 represent a small part of the missing substance that is excluded from corporate legal analysis by the axioms of the CLDM. This missing substance reveals the limits of corporate legal disciplines, and underscores that prominent legal instruments in CL, CG and CSR are constructed on a partial analysis of corporate agents, the corporate form, corporate interaction, state-corporate relationships, behavioural models and markets. The fact that this analysis is partial, and that this

${ }^{34}$ See section 5.2.6. 
partiality can be attributed to the theoretical substance of corporate legal disciplines, was not sufficient for us to conclude that CL, CG and CSR are failing to align ExpCB and TNC behaviour. We argued that we could only draw such a conclusion if this missing substance has a significant impact on corporate legal analysis and contributes towards misalignment between ExpCB and TNC behaviour.

\section{Chapter 6: Evaluating the success of corporate legal disciplines and regulation}

Chapter 6 evaluated this impact and contribution, and thus the success of corporate legal disciplines, using two approaches: (1) a methodological evaluation of corporate legal disciplines and regulation; and, (2) an applied comparison of the two sets of causes of misbehaviour to a case study. The first section outlined the methods for, and findings of, the methodological evaluation. ${ }^{35}$ The second section outlined methods for the applied comparison and explained the decision to use Enron as a case study to evaluate the various causes of TNC misbehaviour. Sections three and four applied corporate legal and non-corporate legal causes of misbehaviour to the Enron case study.

The first section, the methodological evaluation, relied on Kuhn's theories on disciplinary matrices and our earlier analysis of the CLDM to develop a methodological test for the success of corporate legal disciplines. ${ }^{36}$ It used the public interest purposes underpinning $\mathrm{CL}, \mathrm{CG}$ and CSR to develop the following accuracy-based test for the methodological performance of disciplinary matrices: Do the abstractions produced by the conceptual tools of a disciplinary matrix reflect as-accurately-as-possible the complex reality of the problems it seeks to address? This general test was reformulated to evaluate corporate legal disciplines: Does the CLDM rely on an as-complete-as-possible range of symbolic generalisations, models, exemplars and schools of thought in relation to philosophy of science, theories of society, theories of human behaviour and theories of the corporation?

The evaluation concluded that no, the CLDM does not rely on an as-complete-as-possible range of theoretical concepts. Although it recognises various models of the corporation, the CLDM seems to rely solely on liberal-economic theories of society and a narrow range of economic theories on human behaviour. This means that CL, CG and CSR are generally constructed on a partial, arguably reductionist, understanding of the relationships between corporations and society. Corporate legal disciplines are therefore methodologically precluded from successfully aligning ExpCB and TNC behaviour; CL, CG and CSR can achieve no more than suboptimal results, which means that they are failing to align ExpCB and TNC behaviour.

\footnotetext{
${ }^{35}$ See section 6.1.

${ }^{36}$ See section 6.1 .
} 
The methodological evaluation also identified that the methods of CL, CG and CSR are contributing towards the technocratic realisation of a market fundamentalist corporate utopia. Implicit but ubiquitous reliance on liberal-economic models of society, combined with a virtual absence of discussion on the political nature of these models, means that researchers using the methods and theories of prominent $C L, C G$ and CSR instruments are methodologically predetermined to shape social arrangements in accordance with the political designs of economic liberalism. We found no central strand of discussion in the corporate legal literature on the political nature of corporate legal scientific practice or the creation of this corporate utopia. This suggests that there is a deficient understanding in the corporate legal scientific community about the political nature of their scientific practice, and how it may implicitly serve the interests of corporations rather than the public interest.

The second, third and fourth sections, comprising the applied comparison, examined whether corporate legal and non-corporate legal causes could explain (parts of) the Enron scandal as described by news articles, academic and popular literature. ${ }^{37}$ The first finding was that evidence for all causes of TNC misbehaviour - both corporate legal and noncorporate legal - could be identified in the Enron case study. The second finding from the applied comparison was that the problem descriptions generated by these causes are not contradictory or incompatible; although corporate legal and non-corporate legal causes are built on different underlying assumptions and analytical techniques, their findings are ultimately complementary. This complementarity indicates that both sets of causes can help corporate legal researchers understand and regulate TNC misbehaviour. We found no evidence to suggest that (part of) one set of causes should seek to displace the other. The third finding was that corporate legal disciplines and regulation are operating suboptimally since they address only part of the causes of TNC misbehaviour. This flows logically from systemic corporate illegality ${ }^{38}$ and the fact that prominent corporate legal instruments only capture issues associated with the first, corporate legal, set of causes. ${ }^{39}$ We could attribute at least part of this ineffectiveness to the substance of non-corporate legal causes which is absent from corporate legal disciplines and regulation.

The methodological evaluation and applied comparison both concluded that CL, CG and CSR are not succeeding in aligning TNC behaviour with corporate legal expectations. These disciplines are therefore failing to fulfil their public interest purposes. This provided a negative answer to the first $M R Q^{40}$ that was posed in the introduction to this research.

\footnotetext{
37 See sections 6.2, 6.3 and 6.4.

38 See Chapter 3.

39 See Chapter 4.

${ }^{40}$ Are corporate law, corporate governance and corporate social responsibility successfully aligning transnational corporate behaviour with corporate legal behavioural expectations?
} 
The failure of CL, CG and CSR was not reflected in an inability of these disciplines to address misbehaviour; we confirmed that they are perfectly capable of diagnosing problems and providing solutions. Instead, we found that the failure of these disciplines was reflected in suboptimal results and persistent TNC misbehaviour, which these disciplines seem able to explain but may be too methodologically impaired to adequately understand or resolve in accordance with the public interest. We concluded this Chapter by identifying two structural issues with CL, CG and CSR: they are methodologically suboptimal and exhibit political bias in their scientific practice.

\section{Chapter 7: Reforming corporate legal disciplines and regulation}

Chapter 7 explored what we can do about the methodological suboptimality and political bias of corporate legal disciplines and regulation. It first identified that the global focus of this research, which enabled us to identify that there is a need to reform CL, CG and CSR, is unfortunately not a sufficient basis for specifying detailed reforms in particular jurisdictions. We subsequently limited the scope of this Chapter to proposals for stimulating debate on the theories and methods of corporate legal disciplines and regulation.

The first section focused on countering methodological suboptimality and provided seven discussion areas with new theories and methodological techniques for corporate legal analysis. ${ }^{41}$ The second sub-section sought to mitigate political bias in corporate legal disciplines and regulation by advocating that we regulate corporations as sui generis legal tools outside the confines of the public-private divide. ${ }^{42}$

The first section, on the methodological suboptimality of corporate legal disciplines and regulation, proposed seven areas of discussion in separate sub-sections:

1) Rethinking the public interest as an inchoate concept;

2) Confluence of interest theory;

3) Revisiting the relationship between rationality, harm and action;

4) Investigating the relationship between corporate agent morality and free will;

5) Addressing market fundamentalism in corporate legal disciplines and regulation;

6) Using Exchange Opportunity Assessments to regulate markets and exchange opportunities;

7) Developing an impartial framework for corporate legal analysis.

The first subsection outlined how we can use the public interest to guide research practice and reforms. It did not provide a precise definition but indicated that we would rely on the

\footnotetext{
${ }^{41}$ See section 7.1.

42 See section 7.2.
} 
public interest as an inchoate concept and locus for the expression of legitimate, competing principles. This enables us to discuss reforms options while maintaining a balance between environmental, social, economic, social, cultural and other interests; a precise definition would have created a hierarchy between these interests and could result in methodological determinism and bias.

The second sub-section, on confluence of interest theory, described how researchers can expand their analytical techniques to examine confluences of interest. These were defined as follows:

Confluences of interest (hereafter 'confluints') are tacit standards of behaviour which operate beyond the formal, publicised rules and standards of an organisation. They arise because social, organisational, political, economic, cultural and other factors make it personally and organisationally preferable for rational, self-interested corporate agents to converge on a certain behavioural standard. Confluints are not legal obligations or formal organisational requirements. They are unwritten because it would be counter-productive to formalise them.

This section identified and discussed the complementary relationship between agency theory and confluint theory. The former examines conflicts of interest between various principles and agents in the corporation; the latter considers how personal and organisational interests may converge on a certain standard of behaviour. We subsequently explored the concept of confluints and identified three examples:

1) Corporate agents should maximise the corporate share of surpluses during the negotiation of exchange opportunities and should disregard the consequences of negotiation outcomes except insofar as they may impact corporate interests;

2) Corporate agents should, when producing communications or complying with transparency requirements, promote and protect corporate interests even if this risks misleading others;

3) Corporate agents should discourage external whistleblowing insofar as doing so is unlikely to invite legal, reputational and other risks.

We verified these confluints against the definition above and demonstrated how they could be used to develop reform proposals. We suggested that confluint theory enables researchers to examine one facet of corporation and corporate agent behaviour that has thus far escaped systematic analysis.

The third sub-section examined the relationship between rationality, harm and action. It identified an apparent presumption in corporate legal disciplines and regulation that corporate agents with monitoring and control rights are capable of identifying harm and 
that they will respond mechanistically to instances of misbehaviour. Yet the Enron case study showed that numerous agents did not act automatically to address harmful behaviour at Enron. They may even have struggled to determine whether certain activities were harmful or beneficial to the organisation: at what point does financial manipulation become illegal and begin to undermine, rather than support, a company's existence? These findings suggested that it is wrong to presume that agents with control and monitoring rights respond mechanistically to instances of misbehaviour.

We subsequently noticed that this presumption rests on a further assumption that harm is a discrete and objective phenomenon; i.e. there is a universal standard for deciding whether something is harmful and how harmful it is. If harm is not modelled as discrete and objective, then any action following misbehaviour would first require discussions on whether a harm occurred, the extent to which it was harmful, and how it should be compensated. This would make it impossible to presume that corporate agents respond predictably to instances of harm. We subsequently offered a reform suggestion that corporate legal disciplines and regulation should also model harm as a subjective, dynamic and contingent concept.

The third sub-section also identified that corporate legal disciplines and regulation may be relying on the logic of ancient Greek rationalism, where rational action is determined by the content of social roles rather than the characteristics and circumstances of individual corporate agents. If roles establish rational behaviour, then a failure to respond to misbehaviour is simply irrational. If, however, we do not assume that rationality leads automatically to action - and that individuals are not automatons acting out social roles then we can see that control and monitoring rights endow individuals with the freedom to decide whether they want to exercise these rights (or not). The question for reformers is then why individuals with monitoring and control rights do or do not exercise these rights. We noted that, if we step out of the social role-based framework of ancient Greek rationalism, then we can ask this question without immediately presuming that a failure to monitor is incompetent or irrational.

The fourth sub-section reflected on corporate agent morality and free will. It argued that corporate legal disciplines and regulation's reliance on ancient Greek agency models may be undermining the extent to which corporate agents can exercise free will. The starting point was to identify that, in ancient Greece, the rational action of fathers, women, slaves and others was determined by the different social roles that they occupied in a cosmological framework known as the 'great chain of being'. Individual rationality was measured by the extent to which a person could understand and act in accordance with their role in this unequal 'natural' order. 
We next identified a comparable corporate legal cosmology, namely a 'natural' transnational capitalist order populated by people with given social roles as shareholders, employees, directors, consumers and so on. People are generally expected to behave in accordance with these roles, whose substance is rationally and scientifically divined from common practices assessed against the perceived logic of an idealised capitalist order. Inequality between these various roles is taken for granted and treated as a 'natural' part of this capitalist cosmology.

We subsequently considered how the rise of Christianity introduced the concept of free will and radically altered ancient Greek agency models. Instead of individual action being determined by unequal social roles, Christianity presumed that all individual 'souls' are equal and that the behaviour of these equal souls should be judged in accordance with the universal standards of Christian doctrine. Regardless of whether you are a father, woman or a slave, your actions would henceforth be judged in the 'eyes of God,' through Christian doctrine, rather than simply being derived from your social position. This introduced a separate step between deliberation and action, 'willing,' where the faithful could exercise their individual 'free will' and assess the morality of different courses of action.

Liberalism is built on the egalitarian premises and free will-based agency of Christianity. This stands in contrast to the way that corporate legal disciplines and regulation have constructed an unequal cosmology based on ancient Greek-style agency models. The latter approach has reified the social roles of the transnational capitalist order, turning the content of these roles into an 'objective', 'natural' and 'timeless' fact. This seems to be undermining the capacity of individuals to exercise their free will and individual morality; they are expected to simply behave in accordance with the role-based morality of the idealised transnational capitalist order. In terms of reforms, we suggested that ethical behaviour may be promoted by measures which:

1) Stimulate moral reasoning, understanding and action from the perspective of individual free will in accordance with a wide range of universalist moral standards;

2) Discourage moral reasoning, understanding and action from the perspective of social roles which are derived from the supposed 'nature' of idealised capitalist cosmology.

These measures represent a conceptual shift away from an inegalitarian corporate cosmology, towards an egalitarian paradigm where individual free will and universal moral standards are empowered and used to socially embed corporate activities and nurture the moral capacity of corporate agents. 
The fifth sub-section examined market fundamentalism in corporate legal disciplines and regulation. It first argued that market 'intervention' is not a neutral term but rather one with implicit market fundamentalist content concerning the appropriate relationship between states and markets. It suggests that markets are separate from government activities, and that government activities risk disrupting or 'intervening in' something which is already there. It furthermore implies that a society with maximal exchange opportunities is a 'state of nature' for human affairs; i.e. it was possible to exchange everything before social, political and other factors intervened and limited the extent to which humans could exchange goods and services.

This led to the second argument, namely that market fundamentalist misconceptions on the role of government may have made it difficult for corporate legal disciplines and regulation to distinguish between market and government failure. If we assume that the overarching responsibility of governments is to establish efficient market functioning, then market failures are a government failure and government failures are market failures. We indicated that corporate legal researchers can avoid this conceptual trap by recognising that markets are socially constructed ${ }^{43}$ and by imbuing governments with a broader purpose than the promotion of efficient markets.

The final part of this sub-section reflected on how corporate legal researchers can balance market-based and non-market-based approaches; this balance is currently difficult to achieve due to market fundamentalism in corporate legal disciplines and regulation. We found that viewing the economy as 'one big market' undermines the ability of researchers to distinguish between different markets and regulate them appropriately. It also makes it difficult for researchers to properly account for the non-economic aspects of market exchange. We concluded that analysing markets as social constructs should grant corporate legal researchers a deeper understanding of the relationship between markets and regulation, and may enable them to conscientiously design and regulate markets as a matter of public policy.

The sixth sub-section presented Exchange Opportunity Assessments (EOAs) as an impartial tool to evaluate the regulation of markets and exchange opportunities without succumbing to biases either for or against market-based approaches. The purpose of EOAs is to evaluate whether particular exchange opportunities should be permitted, regulated or forbidden in accordance with the public interest. They comprise two parts:

${ }^{43}$ See section 5.2.6. 
Part 1: An impartial inventorisation of potentially applicable theories and methods from different disciplines for determining whether and how a specific exchange opportunity could be permitted, regulated or forbidden;

Part 2: Normative arguments concerning why and how, in light of the impartial inventory, this exchange opportunity should be permitted, regulated or forbidden.

Part 1 should be developed through interdisciplinary cooperation. Part 2 invites researchers from various disciplines to normatively argue how they believe that an exchange opportunity should be regulated (or not). We subsequently demonstrated the use of EOAs by evaluating the regulation of share buybacks using a barebones version of these two parts. A promising feature of these tools is that they are open to collaboration, interdisciplinarity, adaptation, enhancement and mutual learning over time. They address the suboptimality of corporate legal disciplines and regulation by departing from methodological determinism ${ }^{44}$ and offering an incremental approach to reducing the effects of market fundamentalism.

The seventh sub-section outlined how we can develop an overarching, impartial framework for corporate legal analysis that is not subject to methodological determinism. Recalling our earlier finding that every corporate legal reform proposal builds on one or more theories of human behaviour, theories of society and theories of the corporation, we considered that corporate legal analysis could benefit from developing pluralist inventories of these theory areas in accordance with the accuracy rule. We also argued that corporate legal analysis could benefit from a fourth inventory with analytical frameworks such as those in Chapter 5 . This produced four components for an impartial framework for corporate legal analysis:

1) An inventory of behavioural models and assumptions;

2) An inventory of social theories and methods to structure social arrangements;

3) An inventory of theories of the corporation;

4) An inventory of analytical frameworks to diagnose problems.

Each of these inventories should contain an as-complete-as-possible range of theories and methods in relation to their content. This conforms to the accuracy rule and should help researchers avoid relying too much on a single approach to analysing and regulating corporations. Just like a microscope with different settings or a painter with different

\footnotetext{
${ }^{44}$ See section 6.5.
} 
brushes, this impartial framework could provide corporate legal researchers with a 'multitool' to examine corporations and diagnose problems.

The second section considered how we can mitigate the political bias of scientific practice in corporate legal disciplines and regulation. ${ }^{45}$ It proposed that we regulate corporations as legal tools in order to counter political bias in corporate legal disciplines and regulation. The first sub-section examined liberal democracy as the authoritative blueprint for states under conditions of globalisation, and as the theoretical context in which corporate activities are enabled and constrained. It reflected on liberalism, the public-private divide, political liberalism, economic liberalism and democracy to establish a common conceptual ground between the reader and writer.

The second sub-section examined the position of corporations in relation to the publicprivate divide of liberal democratic societies. It first needed to define 'private actor' since a clear definition of this concept seems to be absent from the corporate legal literature:

A private actor is a natural person who, following the deliberate exercise of free will, is responsible for the benefits of their positive acts and the liabilities of their negative acts.

This definition was combined with earlier findings to generate tentative definitions for the public-private divide, private law and public law. We subsequently considered whether corporations can satisfy the ontological requirements of this definition and 'be' a private actor.

We determined that corporations are not private actors because they are not natural persons and cannot engage in free will deliberation. They act, moreover, through corporate agents and not of their own volition, so they do not commit the positive or negative acts which are ascribed to them. ${ }^{46}$ These agents cannot, moreover, exercise free will on behalf of the corporation because they are morally impaired due to their agency roles. ${ }^{47}$ This does not, however, mean that corporations are public actors. Public actors are founded on an egalitarian premise between equal individuals, and corporations are founded on an unequal premise between contributors of capital and others.

Corporations may therefore demonstrate some traits that are public, but they are not public. And they may demonstrate some traits of private actorhood, but they are not private. This led us to suggest that public-private debates in the corporate legal literature may be grounded in a false dichotomy. We argued that this false dichotomy emerged,

\footnotetext{
${ }^{45}$ See section 7.2.

${ }^{46}$ See section 5.2.2.

${ }^{47}$ See section 5.2.1.
} 
first, because the philosophical discussions that laid the foundation for liberal democracies did not focus on corporations but were rather concerned with abuses of state, religious and monarchical power. And, second, because discussions on whether corporations are private or public only emerged once constitutions and the public-private divide had already been established in liberal democratic states.

The second sub-section concluded that the public-private dichotomy is a primary source of political bias in the scientific practice of corporate legal disciplines and regulation. This dichotomy entombs researchers in liberal discussions on the appropriate relationship between individuals and states and fails to recognise that corporations are not individuals or states, but sui generis entities. Even mixed and pluralist positions, which argue that corporations are hybrid public-private entities, cannot escape the effects of this political framing. We closed this sub-section with an invitation for corporate legal researchers to step out of the politicised confines of this false dichotomy in order to regulate corporations in accordance with the public interest.

The third sub-section picked up this challenge and reflected on the development of a new legal framework for corporations as sui generis entities. It examined how corporations could be regulated as legal tools without disrupting the existing public-private framework of liberal democracies. We did not argue that corporations are nothing more than legal tools, ${ }^{48}$ but rather that framing their existence as legal tools is a useful fiction to help us regulate their activities in the public interest. We presented three arguments in favour of this approach and discussed each in turn:

1) A re-defined relationship between liberalism, the public-private divide and corporations as legal tools may help delineate an appropriate range of corporate rights and safeguard individual rights and public interests;

2) Corporate status as legal tools will enable judges, corporate legal researchers and policy makers draw necessary distinctions between different kinds of corporations. This may help address misbehaviour and facilitate regulatory experimentation and judicial decision-making;

3) Classifying corporations as legal tools does not have to produce any immediate shocks to the economy or the way in which corporations are regulated, yet it does facilitate an extensive, long-term overhaul of the current system.

The first argument explained that corporations and individuals are, by virtue of their contracts, currently embedded in a regime of private actor rights and protections. This 'web of individual rights' shields corporations from being regulated as sui generis entities

\footnotetext{
${ }^{48}$ The accuracy rule establishes that there are, and should be, many perspectives on what a corporation 'is'.
} 
in the public interest. We identified, however, that contractual, private actor protections for corporations and between corporations and individuals may be unjustified because these exchange relationships are unable to satisfy the ontological requirements of private actorhood. Moral impairment, separate legal personality and limited liability entail that contracts between corporations and natural persons are not an exchange between private actors. Shareholders with limited liability, for example, do not bear the (full) liabilities of the corporation in which they invest, and corporate agents with employee contracts do not bear the (full) liabilities of their acts on behalf of the corporation; this suggests that these parties should lose part of their private actor status in their contractual relations with corporations. These 'non-private contracts' should still receive legal protection, but this does not have to be the same level of protection as a contractual exchange between individual private actors. The recognition of non-private contracts will require a two-tier system of contract law; the existing one for exchanges between individual rights holders and a separate regime for corporations and contractual relations between private actors and corporations. This seems complicated, but these two systems can be differentiated through the inclusion of mandatory default terms in contracts with corporate entities. Importantly, this two-tier system dissolves the web of individual rights and enables the regulation of corporations as sui generis entities.

Turning to the second argument, we first noted that corporate legal disciplines and regulation appear to assume an 'equality of corporate forms,' whereby each corporation in a jurisdiction enjoys, for example, the same degree and kind of separate legal personality and limited liability. This has contributed towards a host of legal problems such as the difficulty to hold parent corporations accountable for the questionable activities of their subsidiaries, or the inability to draw common sense distinctions such as between parent corporations and letterbox companies. Equality of corporate forms entails, moreover, that judicial decisions concerning the corporate form should also be applied to all other corporate forms throughout the economy. The potential of these cascading effects may be contributing towards judicial conservatism, and may make it difficult for judges to differentiate between uses of the same corporate form for different purposes. If we recognise that corporations are not private actors, and regulate them as legal tools, then there is no need for them to inherit the same kind of egalitarian protection that is granted to individuals under liberalism. Similar corporations should be regulated in a similar manner, but this premise should be abandoned when it is contrary to the public interest and results, for example, in corporate impunity for misbehaviour. This approach should help corporate legal researchers, policy makers and judges draw reasonable distinctions between different kinds of corporations.

The last argument is simple but perhaps the most significant. If we recognise that corporations are legal tools, and ascribe all existing corporate rights and obligations to the 
initial version of this tool, then we can use incremental legislative and judicial changes to re-regulate corporate activities. This radically changes the conceptual foundation for corporate regulation and opens the door for a significant overhaul, but it creates no immediate shocks. People are still free to use corporations and the role of corporations in the economy is preserved. This enables us to gradually shift away from a public-private paradigm without chaotic disruption to the economy. Remarkably, the fact that corporations are not private or public actors means that this change may be more congruent with liberal democratic principles than the existing structure of corporate regulation. There are, in other words, no practical, legal or conceptual barriers to prevent us from examining and re-regulating corporations as sui generis entities and legal tools in accordance with the public interest.

\section{Chapter 8: Conclusion}

The conclusion provided a research summary (more concise than this appendix) as well as research limitations, options for future research and final remarks. This appendix only repeats the final remarks for this Chapter since it is redundant to repeat the other content. These remarks are as follows:

I believe that this book goes to the heart of structural problems in contemporary corporate legal regulation and analysis. It exposes, without arguing from an explicitly normative position, that corporate legal disciplines and regulation can achieve no more than suboptimal results and are fated to produce a harmful corporate utopia. It shows, moreover, how we can stimulate debate on these problems and help ensure that corporations operate in the public interest.

The analysis has been critical of contemporary approaches to corporate legal disciplines and regulation, but it is not an anti-corporate manifesto. We did not adopt an anticorporate stance - no argument was made that corporations are evil, that they should be abolished overnight or that their assets need to be immediately socialised or placed under state control. We may have used stark examples of corporate misbehaviour to demonstrate the contrast between desired and actual corporate behaviour but made no presumption that misbehaviour is the norm for all corporate or corporate agent activities. If there appears to be an anti-corporate sentiment in this work then this stems from my aversion to, and wish to urgently address, the systematically harmful and unsustainable activities of corporations and states under conditions of transnational capitalism. I have conscientiously embraced the bias that comes with seeking to change the status quo and would point out that a failure to question existing conditions is just a different kind of bias.

In this regard it has been concerning, following years of study, to see that so much of the corporate legal literature has unquestioningly adopted a narrow, pro-corporate view of 
the world. It focuses on the minor details, technical issues and best practices of the corporate machines at the heart of our political economy while fundamental assumptions and the pressing issues of our time are side-lined or trapped in unproductive, polarised debates. Yet we have seen that corporate activities, interactions, ethics and harms are much more sophisticated than can be inferred from the orthodox echo chambers of corporate legal analysis.

These structural issues were exposed using interdisciplinary insights, a global focus and an imperfect method. The price of knowledge in this case was to admit the negative influence of generalisations, cherry picking and high levels of abstraction. An astute reader would be correct to criticise the fact that we discussed only part of the literature on liberal democracy. Or that we glossed over many details in national corporate laws. Or that we inadequately described the interests and composition of the corporate class. These and similar criticisms are legitimate, and should be incorporated over time, but they do not detract from our overall conclusion. The methodological suboptimality and political bias of $\mathrm{CL}, \mathrm{CG}$ and CSR do not disappear due to problems with particular examples and arguments. The shortcomings of these disciplines are concrete and can be readily identified.

The problem with $\mathrm{CL}$ is that it takes credit for the benefits of corporations but inadequately considers the full range of social, environmental, economic and other interests that it affects. Its overreliance on legal and market-based approaches, liberaleconomic social models and economic models of human behaviour ensures that it sees no more than part of the picture of corporate (mis)behaviour. It is from this impaired perspective that $\mathrm{CL}$ focuses primarily on empowering corporations and constraining corporate agents on behalf of founders and shareholders. This arguably facilitates private wealth accumulation, national competitiveness and economic growth, but it will do little to address the broad range of harms caused by corporate activities.

We can address these issues by adopting a new and broader perspective on the scientific methods and public interest purposes of $\mathrm{CL}$. This entails, first, that we strive towards an as-complete-as-possible analysis of corporate activities and relationships. And, second, that we direct the techniques and regulation of $C L$ to ensure that corporations promote the social, environmental, political, cultural and economic well-being of our species and other life on this planet. This is not a perfect fix for corporate (mis)behaviour, but it does provide a reasonable normative and scientific foundation for globally maximising the benefits and minimising the harms of corporations as legal tools.

CG has significant international influence, but I would argue that this prestige is largely undeserved. Its scientific foundation is deficient, and it is untenable to presume that a narrow emphasis on shareholder rights will align corporate activities with the public 
interest. CG needs to move away from idealising markets and stop assuming that the socio-political realities of transnational capitalism are an economic law of nature. This approach mystifies and conceals the institutional context and organisational structure of corporations under a blanket of political ideology. This may assist powerful financialeconomic interests - the seminal articles of this discipline are mostly from financial journals - but it is contrary to basic tenets for the scientific analysis of corporations.

At a minimum, CG needs to adequately analyse the political economy of markets, relations between organisations, corporate political activities, bureaucracy in organisations, the influence of hierarchy on decision-making, the effect of self-interest assumptions and the organisational morality of corporate agents. Confidence in CG is undeserved so long as it does not analyse an as-complete-as-possible range of individual, organisational and contextual factors, and so long as it does not measure its success against the actual behaviour and impact of corporations.

CSR promises that we can achieve sustainable development by using market pressures to solve social and environmental problems and turn corporations into responsible, moral actors. This approach can only succeed if markets operate in accordance with ideal theory and if there is no conflict between profit incentives and socially responsible behaviour. The success of CSR depends, in other words, on the spread of markets and continued faith in market fundamentalism. The discipline is well intentioned, but its theoretical premises are suboptimal and counterproductive; it is methodologically predetermined to perpetuate the unsustainable political economy of transnational capitalism.

A corporation that engages with CSR is arguably better than one which does not, but winwin best practices between corporations, communities and employees cannot be universalised as a profitable solution to social, economic and environmental crises. They cannot be the norm for sustainable development so long as institutional conditions and organisational practices rely on anti-social markets, stimulate self-interested shorttermism, allow for systematic illegality and tolerate corporate impunity. Influential approaches to CSR must be reformed to incorporate an as-complete-as-possible picture of the relationships between individuals, corporations and society. They must stop glossing over the interrelated institutional, political and controversial aspects of social, economic and environmental problems.

Biodiversity is plummeting, soil, air and water quality are degrading rapidly, natural systems are collapsing, global emissions are increasing, inequality is escalating, and exploitative economic activities are increasing; far too many social, economic and environmental markers have become progressively worse under the rise of TNCs and transnational capitalism. Corporate legal disciplines are as responsible for these issues as individuals, governments, corporations and others. The difference, however, is that $\mathrm{CL}, \mathrm{CG}$ 
and CSR are better positioned to study the corporate aspects of these issues than the average individual, corporation or government. This heightened responsibility is seldom reflected in the consciousness of our corporate legal scientific practice.

We have instead tended to approach global crises like captives in Plato's cave; missing much of reality while focusing on the traditional shadows of idealised markets and capitalism. One consequence is that we are barely aware that decades of our most influential scientific efforts to regulate corporations have been channelled into suboptimal methods and politically biased pro-corporate research. Too many of us have received a mystified, pro-corporate perspective on social, economic and environmental issues while studying CL, CG and CSR. We have been prepared to work in and on behalf of corporations, but currently lack the intellectual tools to properly deal with the broader issues caused by their activities. This will continue to entrench corporate power and do more harm than good unless corporate legal disciplines and regulation are structurally reformed. Fortunately, we can transcend these problems if we abandon market fundamentalism and adopt the impartial, interdisciplinary approach to corporate legal analysis that was advocated in this research. 